\title{
Negotiating Pragmatics of Student's Writing through Tutorials: A Case Study for Exploring World Japaneses
}

\author{
Kiyono Fujinaga ${ }^{a, b *}$, Seiko Fujiia \\ a Department of Language and Information Sciences, University of Tokyo, 3-8-1 Komaba, Tokyo, Japan \\ ${ }^{b}$ Department of Linguistics, University at Buffalo, 14260, Buffalo, NY, United States
}

*Corresponding author: kiyonofu@buffalo.edu

\begin{abstract}
The aim of the present study is to explore the thin line between a learner's pragmatic failures and styles through their writings and to call for the pragmatic variations of Japanese as a second language in writing such that we establish World Japaneses in the same spirit as World Englishes. In order to achieve this goal, we discuss the role of tutorials in creating a ground of meaning negotiation between peer tutors and students and second the importance of negotiation in choosing the linguistic forms best expressing the non-native students' ideas rather than automatically conforming to the norms of the native speakers. Specifically, this study offers an ethnographic analysis of writing tutoring sessions between an advanced-level Japanese learner and a native Japanese peer tutor. One of the main findings was the student's unique use of honorifics when discussing his own home country, which conflicts with native Japanese expectations of honorific use. We suggest examples that need much discussions between the learner and the teacher/tutor at writing conference sessions in order to determine whether it is a pragmatic failure or a student's style, in the latter a pragmatic variation of World Japaneses. By examining the abovementioned pragmatic phenomena produced by a L2 writer, we attempt to connect theoretical issues in linguistics, especially Construction Grammar- linguistic ideology, and second language pedagogy.
\end{abstract}

Keywords: L2 Japanese writing, pragmatic failure, style, constructions, world japaneses

(C) 2017 Penerbit UTM Press. All rights reserved

\subsection{INTRODUCTION}

What is native-like ability of language? Native-likeness is a very ideational term; learners wish to dismiss their "foreignness" and idealize the native-like norm and teachers tend to view learners' abilities by approximating their similarity to native speakers (Cook, 1999; 2016). Pawley and Syder (1983) observe native-likeness in idiomaticity of language;

It is a characteristic error of the language learner to assume that an element in the expression may be varied according to a phrase structure or transformational rule of some generality, when in fact the variation (if any) allowed in native-like usage is much more restricted. The result, very often, in an utterance that is grammatical but unidiomatic (ibid.:215).

The present study aims to analyze a second-language (henceforth L2) learner of Japanese's pragmatic failures by exploring idiomaticity of language in the interface of pragmatics and syntax (Fillmore, 1981; Fillmore et al. 1988) and calls for the consideration of pragmatic variations in Japanese as a second language. In section 2, we review Thomas's (1983) study on pragmatic failure and define the concepts of pragmalinguistic failure and sociopragmatic failure. We also review the role of peer tutoring and its effect on negotiating pragmatics between tutors and learners. In section 3, we analyze pragmalinguistic and sociopragmatic failures observed in four tutoring sessions between a native Japanese (henceforth L1) tutor and a Japanese L2 learner. In section 4, we discuss an interface between pragmalinguistic failure, sociopragmatic failure, and the learner's style, and finally our conclusion in section 5 considers the connections between theoretical linguistics, language ideology and second language pedagogy.

\subsection{THEORETICAL FOUNDATION OF THE STUDY}

In this section, we will look at previous studies for analyzing our student's writing (section 2.1) and the roles of peer tutorials in terms of pragmatic negotiations (section 2.2).

\section{Pragmatic Failure}

The present research defines pragmatic failure based on Thomas's (1983) classic study. She argues that although it is artificial to subdivide pragmatic failures into two categories, pragmalinguistic and sociopragmatic (which surely overlap to a certain extent), teachers 
can more efficiently assess their students' problems by doing so. Pragmalinguistic failure is defined as follows:

Pragmalinguistic failure, which occurs when the pragmatic force mapped by $\mathrm{S}$ onto a given utterance is systematically different from the force most frequently assigned to it by native speakers of the target language, or when speech act strategies are inappropriately transferred from L1 to L2 (ibid.:99).

Thomas even speculates that "pragmatic overgeneralization is particularly likely to occur where a narrow range of structures in the mother tongue has a wider range of possible 'translations' in the target language" (ibid.:103). We would like to bear this point in mind when we analyze our student's pragmatic failures of Japanese causative in section 3.5. On the other hand, sociopragmatic failure is defined as:

While pragmalinguistic failure is basically a linguistic problem, caused by differences in the linguistic encoding of pragmatic force, sociopragmatic failure stems from cross-culturally different perceptions of what constitutes appropriate linguistic behaviour (ibid.:99).

Thomas (1983) calls caution for teachers when pointing out students' sociopragmatic failures since learners become sensitive when their social judgements are called into question. She argues it is necessary to distinguish two types of pragmatic failures-pragmalinguistic and sociopragmatic - because the two differ with respect to their possible causes and on how teachers should troubleshoot resulting issues. Specifically, she claims the two pragmatic failures are fundamentally different in terms of the types of pragmatic decision-marking involved. According to Thomas (1983), pragmalinguistic failure originates in the wrong choice of linguistic forms to convey a particular utterance force while sociopragmalinguistic failure originates in values or judgments particular to the student's culture. We believe this is a useful distinction, but differ from Thomas (1983) as we believe grammar and our world knowledge are so intertwined in linguistic construction that we cannot always separate pragmalinguistic failure from sociopragmatic failure. Specifically, in section 3.5 we will look at one example where a seemingly pragmalinguistic failure leads to sociopragmatic failure in a L2 student's writing.

\section{Peer Tutorials And Genre-Based Teaching}

As Thomas (1983) stresses, we claim that pragmatic failures are not immediately apparent in their surface forms and thus the intended meaning of an L2 student's utterance can only be revealed through additional discussions. This is why in this section we look at the role of peer tutoring sessions, paying special attention to how they negotiate pragmatic meaning encoded in the student's writings. We will also seek the key to establishing such negotiation ground in genre-based pedagogy (Hyland, 2007).

\section{The Role Of Peer Tutor}

The presence of peer tutors plays a major role in student writing. Peer tutors are often graduate students whose age and social status are rather close to the client students, so the students feel more at ease talking with them rather than with professors or other authority figures (Williams, 2005). We believe this aspect of peer tutoring is crucial for providing background for negotiation as students can freely take turns in the conversation with peer tutors in order to learn how best to express their ideas.

Another study shows one of the most common tutorial activities between native speakers and non-native speakers is mutual cultural exchange and tutors often find the session exciting when they experience this aspect of tutoring (Blau et al., 2002). They argue:

"This richness of the cultural exchange between tutors and [Non-Native English Speaker (NNES)] clients is one of the most rewarding aspects of NNES sessions. It can remind us that we must not condescend to students who, while they may be challenged by the language barrier, come to us with a worldliness and wealth of knowledge that often surpass that of our [Native English Speaker (NES)] clients. Tutors who are curious about other cultures and build a rapport with their NNES clients usually find these sessions enlightening and invigorating" (ibid.:32).

It is easily understandable that different cultures have different assumptions about the world that often induce pragmatic failures between students' first languages and their target languages. We argue the tutors' positive attitudes toward students' pragmatic failures and willingness to learn the underlying the student's background culture facilitates positive negotiation in tutoring sessions. Thus, we would like to highlight this aspect of tutoring as a crucial factor in establishing backgrounds for negotiating pragmatic meaning in student writing.

\section{Genre Pedagogy}

Hyland (2007) stresses the important aspect of genre-based instruction as follows:

Providing students with the "freedom" to write may encourage fluency, but it does not liberate them from the constraints of grammar in constructing social meanings in public contexts. Genre instruction, in contrast, stresses that genres are specific to particular cultures, reminding us that our students may not share this knowledge with us and urging us to go beyond syntactic structures, vocabulary, and composing to incorporate into our teaching the ways language is used in specific contexts. It assists students to exploit the expressive potential of society's discourse structures instead of merely being manipulated by them (ibid.:150).

Hyland (2007) sees grammar and discourse as integrated and his claim is compatible with one of our arguments that syntax and pragmatics are interdependent, as we shall see in our later analysis.

Our present study is based on a student's speech draft for a Japanese speech contest presenting his country's history to a Japanese audience. Needless to say, this is a very genre-specific discourse. His speech is addressed to the majority of Japanese speakers, including judges of the 
contest, hence his language should be in the formal speech style. He also has to think about the deictic relation of him presenting his speech on behalf of his country to Japanese audience.

\subsection{A CASE STUDY}

The data used in this study comes from speech drafts of an advanced Japanese L2 undergraduate student at a Japanese university as well as ethnographies of writing tutoring sessions between the L2 student and L1 graduate student. The L2 student's first language is Mongolian. They worked together towards helping the student write a speech for a Japanese speech contest by holding four writing tutoring sessions, exchanged several emails, and practiced the speech once. We videotaped each session and wrote ethnographic notes to record the tutor's and the student's comments on cultural exchange.

Pragmalinguistic Failure

As Thomas (1983) argues, pragmalinguistic failure occurs when the pragmatic force of learner's utterance is systematically different from that of native speaker's. The example (1) shows an interesting case of pragmalinguistic failure since Japanese speakers would not usually feel motivated to use honorifics when discussing history.

(1)

\begin{tabular}{|c|c|c|c|c|c|c|c|c|}
\hline & $\begin{array}{l}\text { sekaishi } \\
\text { world.history }\end{array}$ & \multicolumn{2}{|c|}{$\begin{array}{l}\text { kagayaku } \\
\text { shine }\end{array}$} & \multicolumn{4}{|c|}{$\begin{array}{l}\text { mongoruteikoku } \\
\text { the.Mongolian. Empire }\end{array}$} & \multirow{2}{*}{$\begin{array}{l}\text { wa } \\
\text { TOP } \\
\text { ga, }\end{array}$} \\
\hline $\begin{array}{l}\text { jinrui } \\
\text { mankind }\end{array}$ & $\begin{array}{l}n i \\
\mathrm{DAT}\end{array}$ & $\begin{array}{l}\text { nasat-ta } \\
\text { do.POL-PAST }\end{array}$ & $\begin{array}{l}\text { igyou } \\
\text { deeds }\end{array}$ & $\begin{array}{l}\text { ga } \\
\text { NOM }\end{array}$ & ooi & $\begin{array}{l}\text { no } \\
\text { NMNL }\end{array}$ & $\begin{array}{l}\text { desu } \\
\text { cop }\end{array}$ & \\
\hline
\end{tabular}

Thomas (1983) claims one of the major causes for pragmatic failure is transfer between the learner's first language and the target language. However, after consulting with Mongolian language specialists, we could not confirm that Mongolian speakers currently use honorifics to discuss history in Mongolia at the moment. Therefore, we would like to argue that this unique use of honorifics by the student was induced from his understanding of Japanese honorific system, rather than transferred from his first language. In other words, he manipulates the force of Japanese honorifics, being humbly grateful to the history of his country. In fact, during the tutorial, when the tutor asked him why he used the honorific marker in the sentence (1), he replied "because we Mongolian think highly of our history, which I believe, is hard to understand for you Japanese speakers".

One could argue that if this is only observed in his writing and not generally observed in Mongolian speakers, then the case like example (1) is his style, not a pragmalinguistic failure. We would like to highlight the aspect of "force" of pragmatics as this term keeps appearing in Thomas's (1983) original study, and claim that the example (1) is a case of pragmalinguistic failure. That is, the use of honorifics forces us to interpret the text within a certain context, such as a social hierarchy system, the feeling of gratitude, the feeling of awe, etc.

Style

The next example (2) demonstrates a case of his own writing style.

(2)

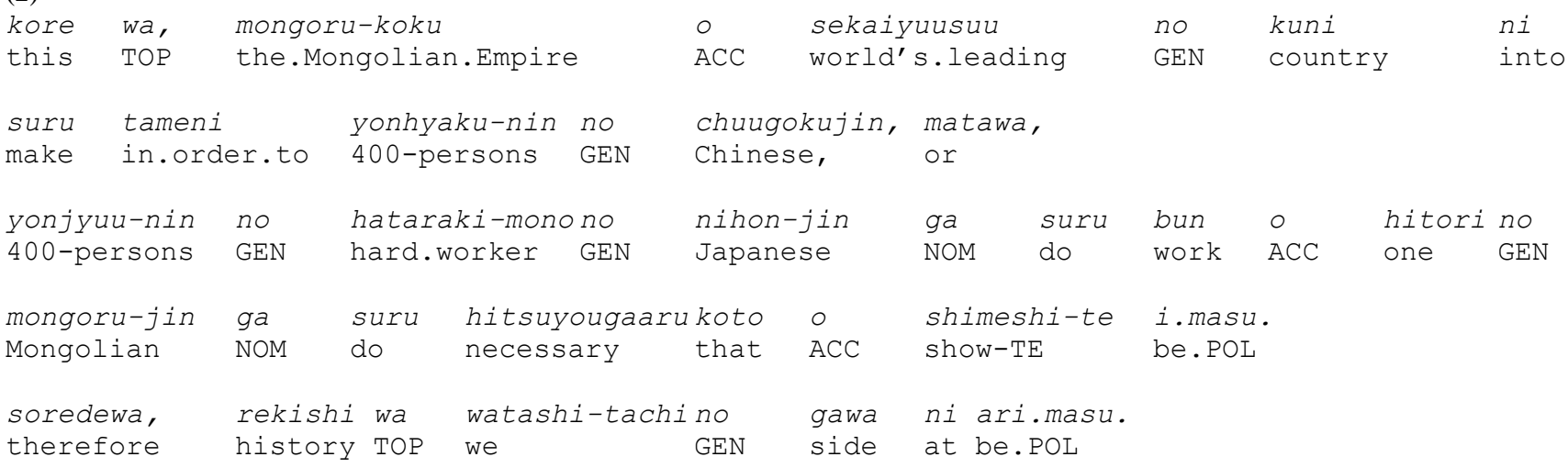

"My point is that in order to make Mongolia world's leading nation one person should do what is done by 400 Chinese or by 40 hardworking Japanese. Only in this case will history will be on our side."

When the tutor asked him the intended meaning of "the history is on our side", he explained "Genghis Khan ruled half of this planet. Each of us Mongolians, if we work together, can do more than what he did. I think history proves my idea." The tutor confessed that although 
she asked many times about his intended meaning, she could never figure it out. Notice in this example, there is no particular pragmatic force like the use of the honorific marker in the first example (1). We are not really forced to interpret the sentence (2) in a certain context.

\section{Interface Of Pragmalinguistic Failure And Style}

The following example (3) is a case where it is difficult to distinguish between pragmainguistic failure and style:

(3)

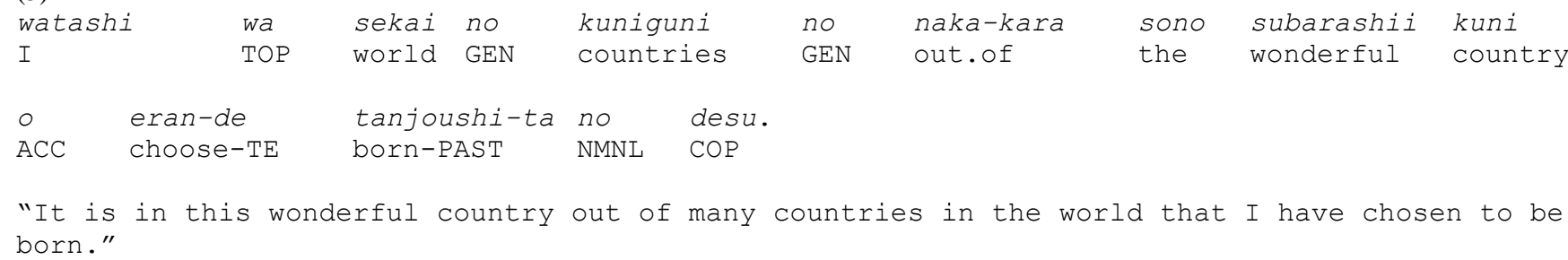

The tutor told us that during the first session she thought this was merely a matter of individual style. However when we consulted with Mongolian language specialist, one of the Mongolian native speakers told us that Mongolian sometimes use the verb "to choose" in a very spiritual way, hence the example (3) may evoke a spiritual context. The example (3) in Japanese sounds a bit poetic, but does not evoke a specific spirituality as Mongolian sounds. Recall in the previous section we made a judgment that the first sentence (1) is an example of pragmalinguistic failure induced within the student's appreciation of Japanese honorific systems and not a transfer from his first language. However, what happens in the third example (3) is likely to result from a pragmatic transfer, where the verb "to choose" in his first language forces us to read the context spiritually whereas the equivalent of Japanese verb does not have the pragmatic force.

\section{Sociopragmatic Failure}

The next example (4) shows the student's sociopragmatic failure. The student claims that his country once dominated many other countries and taught them the lesson of being independent.

(4)

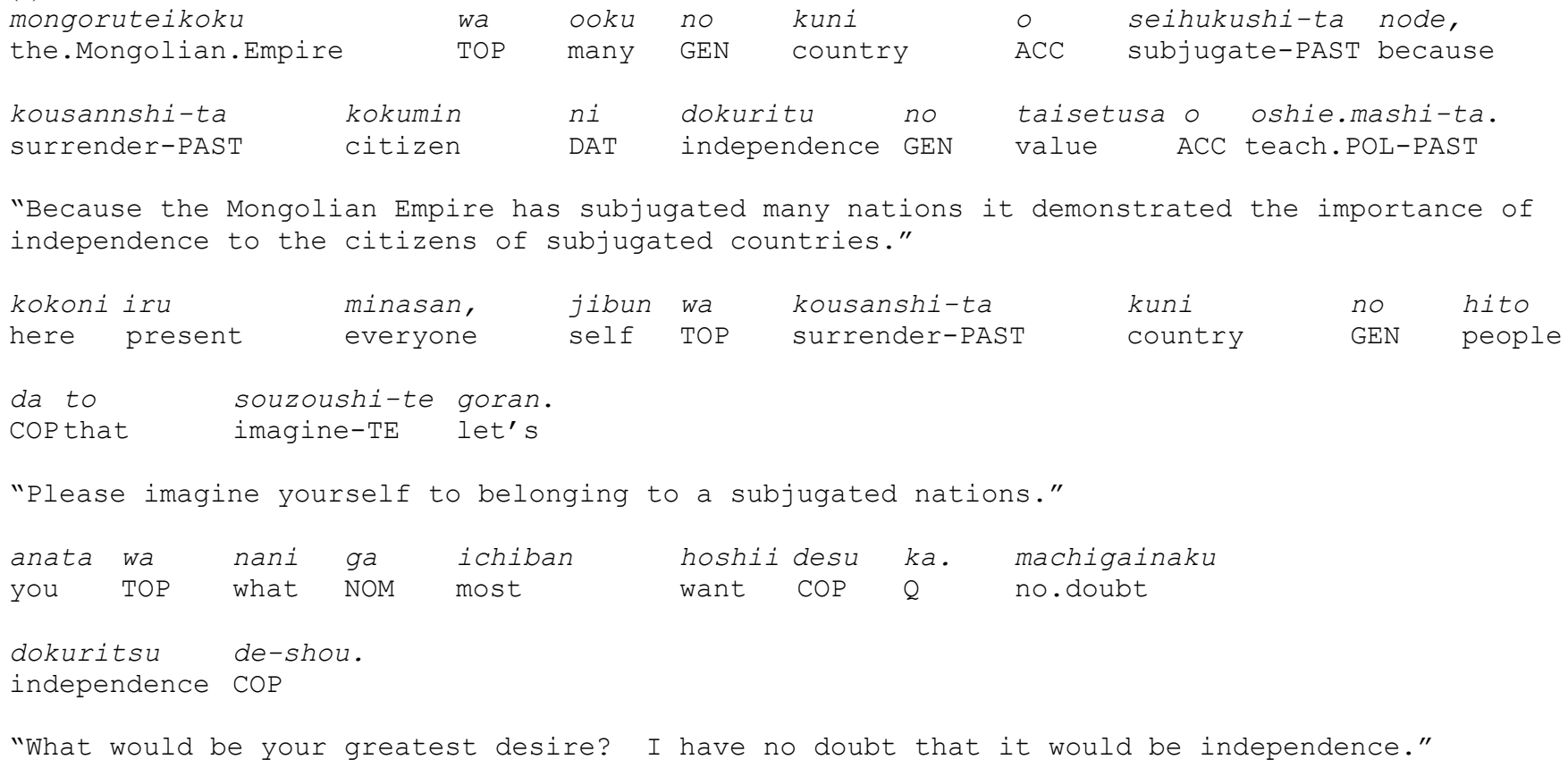

The tutor advised him that this statement may sound offensive to some of his audience at the speech contest because the audience would inevitably contextualize his speech with him representing a voice of the subjugating side as opposed to subjugated countries. It is doubtful that someone not historically or politically connected with this dominator-dominee relationship uttering these sentences (4) would bring about the same effect as he did. We think that the student presenting this is more powerful and offensive than if it is being uttered by someone from another cultural background since social deixis (Fillmore, 1997) plays a role here, namely him being from the empire which once subjugated many countries and his audience being foreigners. It might perhaps even be a case of discourse deixis (Fillmore, 1997) too in terms of the prior existing context where he discussed the excellence of his own country. In other words, he established a prior context that affects how we frame his preceding statements while we make logical connections as we read. In sum, the student's sociopragmatic failure should be advisedly discussed from the perspective of such deixis roles, rather than being pointed out that this whole passage is wrong or misleading. 


\section{Interface Of Pragmalinguistic Failure And Sociopragmatic Failure}

We have discussed so far pragmalinguistic failure and sociopragmatic failure respectively following Thomas's (1983) study. In this section, using the two cases below, we would like to argue these two types of failures cannot always be separated. Moreover, pragmalinguistics failure could invite unwanted judgement upon learners, which was previously discussed under the scope of sociopragmatic failure in Thomas's (1983) study.

(5)

minasan ni atarashii chishiki o atae-tai to omoi.masu.

you all DAT new knowledge ACC give-want that think.POL

"I would like to give you all some new knowledge."

The verbs of giving and receiving are deictic and used to indicate social relationship among the speakers and their references in Japanese (Shibatani, 2003). The sense of relational hierarchy is encoded in these verbs so the student use of ataeru 'to give' sounds very imposing in a way that he represents himself higher than his audience by means of giving knowledge. Grammarians would say that the example (5) is grammatical however we native Japanese speakers would not choose the word ataeru 'to give', so the student's intentions pragmalinguistically fail. More importantly, due to the nature of the verbs of giving and receiving in Japanese it is also an example of sociopragmatic failure.

The next example shows a rather different type of failure than the definition of pragmalinguistic failure and sociopragmatic failure in Thomas (1983).

(6)

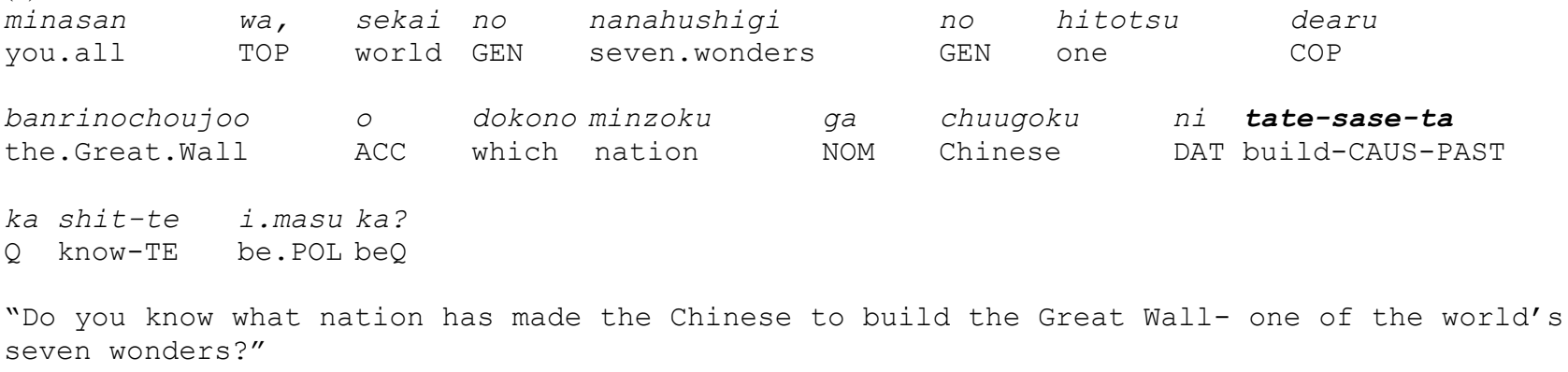

The tutor, without the knowledge of the historical background of the Great Wall, thought of a possible context where the Mongolian empire forced Chinese people to build the Great Wall for Mongolian's benefit. The use of the causative marker -sase evokes a forcing frame. On the other hand, the writing tutoring session reveals that this is not historically true and the student uses the morpheme -sase in the sense of indirect causative. So more precise translation would be "due to the ever-increasing power of the Mongol empire, the Chinese had to build the Great Wall." So here we can observe a semantic failure. As discussed in (4), the awkwardness of the sociopragmatic failure originated in the mislocation of social deixis and discourse deixis in his speech. Similarly in (6), if someone did not know the historical background of the Great Wall they might miss his semantic meaning and interpret (6) as the forced laboring reading. Then the audience might even further consider him an arrogant person, which is a classic result of sociopragmatic failure. In fact, the morpheme-sase, attached to a verb stem, presents other meanings, other than just direct causation. For example, indirect causation is a major reading too as in Okaasan no sonzai ga watashi o tuyokusaseta. "Having a mother like her made me strong." However, here Japanese speakers would have the direct causation reading especially when the causative construction consists of an influential nominative subject and influenced dative object. Notice the subjects in indirect causatives are not necessarily the direct causes for influencing their dative objects,as in the example okaasan no sonzai ga watashi o tuyokusaseta; indirect causatives often take inanimate subjects. The direct causative construction of nominative subject + dative object + the morpheme -sase are so strong that a Japanese speaker could not help but read the example (6) as direct causation. In this case this direct causation reading lead to an unfortunate sociopragmatic failure where the speaker represents the voice of the empire, and this could leave his audience with a negative impression.

In either example, the key point is that syntax, pragmatics and social attitudes/judgments are all interdepent (Fillmore, 1981) and that linguistic constructions show this fact. This is why the student's pragmalinguistic failures could lead to the effect of sociopragmatic failures.

\subsection{DISCUSSION}

So far, we have looked at the examples of pragmalinguistic failures and sociopragmatic failures in accordance with Thomas (1983). Thomas studied pragmatic failure to raise meta-pragmatic awareness for students to express their ideas as they intend;

Recognizing the pragmalinguistic/sociopragmatic distinction means allowing the foreign student the right to flout in exactly the same way as the native-speaker does, and acknowledging that 'speaking good English' does not necessarily mean conforming to the norms of the culturally hegemonic strata. Our only concern as language teachers is to ensure that the learner knows what s/he is doing (ibid.: 110).

In agreement with Thomas (1983), we would like to bring in a notion of World Japaneses as pragmatic variations of Japanese. Japanese is not recognized as an official language by any nation besides Japan and there is no outer-circle to this language if compared to World 
Englishes variations (Kachru, 1992). However there are a fairly large number of Japanese L2 users in the world, 3,984,538 (8 ${ }^{\text {th }}$ July, 2013, Japan foundation), so we would like to suggest we could expand the horizon of Japanese regarding their pragmatic variations as we have seen some examples in the present paper. The examples like odd use of honorifics as in (1) or the (2) and (3), which are arguably the student's style too, should be taken in a more positively light in this regard.

However, while we agree with Thomas's (1983) attitude towards how it is ultimately up to the student to select linguistic expressions, teachers should inform their students that their linguistic construction choice could also have an impact on how their audience evaluates them as well. That is, we have shown pragmalinguistic failure could link to uninvited sociopragmatic failure as in examples (5) and (6). We propose that both teachers and the learners can accept more and more pragmatic variations of Japanese as World Japaneses as long as learners' choices do not make them socially inept and that even "at the grammar level" their choices could create bad impressions by the native speakers. We believe by allowing pragmatic variations of World Japaneses, L2 Japanese users can interact with us with their wealth of knowledge.

\subsection{CONCLUSION}

In this study, we have examined peer-tutor writing sessions in the preparation for the student's Japanese speech contest. First we have reviewed a previous study conducted by Thomas (1983) to define the term pragmatic failures. We then reviewed the role of peer tutorials as cultural consultant as well as the language consultant. We pointed out some student's pragmatic failures contain both pragmalinguistic and sociopragmatic failures aspects in order to show that syntax, pragmatics and social values are all closely interdependent in linguistic constructions. Finally, we proposed the idea of World Japaneses in favor of Japanese L2's pragmatics variations as long as they can best express their ideas and the learner's personality not called into questions by making the variation choice.

$\begin{array}{ll}\text { Abbreviations } \\ \text { ACC } & \text { accusative particle } \\ \text { CAUS } & \text { causative } \\ \text { COP } & \text { acoppula } \\ \text { DAT } & \text { dative particle } \\ \text { GEN } & \text { genitive particle } \\ \text { NMLZ } & \text { nominalizer } \\ \text { NOM } & \text { nominative particle } \\ \text { PAST } & \text { past tense form } \\ \text { POL } & \text { polite form } \\ \text { Q } & \text { question } \\ \text { TE } & \text { conjuctive particle } \\ \text { TOP } & \text { topic particle }\end{array}$

\section{References}

Blau, S., Hall, J. \& Sparks, S. (2002). Guilt-Free Tutoring: Rethinking How We Tutor Non-Native-English-Speaking Students, Writing Center Journal, 23(1), 23-44. Cook, V. (1999). Going beyond the native speaker in language teaching, TESOL Quarterly, 33(2), 185-209.

Cook, V. (2016). Where Is the native speaker now?, TESOL Quarterly, 50(1), 186-189.

Fillmore, C. J. (1981). Pragmatics and description of discourse, In P. Cole (Ed.), Radical Pragmatics, 143-166. New York: Academic Press.

Fillmore, C. J., Kay, P, \&.O'Connor, M. C. (1988). Regularity and idiomaticity in grammatical constructions: The case of let alone. Language, 64(3), 501-538.

Fillmore, C. J. (1997). Lectures on Deixis. CSLI Publications.

Hyland, K. (2007). Genre pedagogy: Language, literacy and L2 writing instruction. Journal of Second Language Writing, 16(3), 148-164.

Kachru, B. B. (1992). The other tongue: English across cultures (2nd ed.).Urbana \& Chicago: University Of Illinois Press.

Pawley, A. \& Syder, F. H. (1983). Two puzzles for linguistic theory: Nativelike selection and nativelike fluency. In J. C. Richards, \& R. W. Schmidt (Eds.). Language and communication (pp. 191-225). London: Longman.

Shibatani, M. (2003). Directional verbs in Japanese. In E. Shay, \& U. Seibert (Eds.). Motion, direction and location in languages: In honor of Zygmunt Frajzyngier (pp. 259-286). Amsterdam: John Benjamins Publishing Company.

Thomas, J. (1983). Cross-cultural pragmatic failure, Applied Linguistics, 4(2), 91-112.

Williams, J. (2005). Writing center interaction: Institutional discourse and the role of peer tutors. In K. Bardovi-Harlig, \& B. S. Hartford (Eds.), Interlanguage pragmatics: Exploring institutional talk. Mahwah, N. J.:Lawrence Erlbaum. 